\title{
A Geografia na política de currículo: quando a integração reafirma a disciplina ${ }^{*}$
}

\author{
Hugo Heleno Camilo Costa** \\ Alice Ribeiro Casimiro Lopes ${ }^{* * *}$ \\ DOI: $10.1590 / 0103-7307201607910$
}

\section{Resumo}

Este artigo focaliza a interdisciplinaridade como expressão de um dos sentidos de currículo integrado nas políticas para o Ensino Médio. Buscando desenvolver tal investigação, analisam-se documentos oficiais: Parâmetros, Orientações complementares aos Parâmetros e Orientações Curriculares Nacionais, com atenção à disciplina Geografia. A partir da abordagem ao ciclo de políticas de Ball, discutimos os textos oficiais como representações de um conjunto mais amplo das políticas de currículo. Com Goodson, analisa-se a relação entre as disciplinas acadêmica e escolar, tendo em vista discursos em defesa da interdisciplinaridade. Problematiza-se a influência da comunidade disciplinar na definição das políticas para Geografia, ao argumentar que, apesar de proposta como via de integração curricular, a interdisciplinaridade tende a ser ressignificada como característica da ciência geográfica nos textos específicos, possibilitando que, de forma híbrida, o discurso disciplinar seja apoiado pela ideia de integração curricular.

Palavras-chave: políticas de currículo, ensino de Geografia, interdisciplinaridade, comunidade disciplinar, Ensino Médio
* Apoio: Ministério da Ciência, Tecnologia e Inovação, Conselho Nacional de Desenvolvimento Científico e Tecnológico; Faperj; UERJ

* * Universidade do Estado do Rio de Janeiro (UERJ), Faculdade de Educação, Rio de Janeiro, RJ, Brasil. hugoguimel@yahoo.com.br

*** Universidade do Estado do Rio de Janeiro (UERJ), Faculdade de Educação, Rio de Janeiro, RJ, Brasil. alicecasimirolopes@gmail. com 


\title{
The Geography in the curriculum policy: when the integrated curriculum reaffirms the discipline
}

\begin{abstract}
This paper focuses on interdisciplinarity as one of the meanings of integrated curriculum in the high school curriculum policy. We analyze the Brazilian Curriculum Parameters and the National Curricular Proposals regarding Geography. Based on Ball's policy cycle approach, we treat the documents as representations of a whole ensemble of curriculum policy. Based on Goodson, we analyze the relationship between the academic discipline and the school subject, considering the interdisciplinarity discourse. We discuss how the disciplinary community influences the Geography curriculum policy, and how the interdisciplinarity tends to be seen as characteristic of the Geographic Science. In this case, the integrated discourse, in a hybrid way, supports the disciplinary discourse.
\end{abstract}

Keywords: curriculum policy, Geography Education, interdisciplinarity, disciplinary community, High School 


\section{Introdução}

Este artigo se sustenta na busca pelo aprofundamento da compreensão de diferentes momentos das políticas de currículo para ensino de Geografia. Sem pretender a construção de uma abordagem final sobre a política, entendemos a socialização das investigações que produzimos como forma de ampliar perspectivas que julgamos potentes para a leitura do dinamismo político.

Em trabalho anterior (Costa \& Lopes, 2009), discutimos as tensões entre os discursos do currículo integrado e disciplinar, tomando por objeto o texto dirigido à área de Ciências Humanas dos Parâmetros Curriculares Nacionais para o Ensino Médio (Ministério da Educação e Cultura - MEC, 1999). Analisamos a relação entre as competências, a interdisciplinaridade e a disciplinaridade, acenando aos significantes cultura, social e sociedade como meios pelos quais também se estabelecia o embate entre a integração curricular e o currículo disciplinar.

Posteriormente (Costa \& Lopes, 2011), tendo em vista a ênfase na ideia de interdisciplinaridade em sua relação com a Geografia, não só nos PCNEM como nos textos das Orientações Complementares aos Parâmetros Curriculares Nacionais (PCN+) (Ministério da Educação e Cultura - MEC, 2002) e das Orientações Curriculares Nacionais para o Ensino Médio (OCNEM) (MEC, 2006), discutimos o quanto perspectivas interdisciplinares tendem a ser suportadas por distintos matizes do pensamento geográfico que, por sua vez, são reinterpretados na política como embasamento a uma visão interdisciplinar geográfica.

Atentamos mais uma vez à ideia de interdisciplinaridade como expressando um dos sentidos do discurso de integração curricular posto em evidência pelas políticas para o Ensino Médio, defendendo, contudo, o quanto a interdisciplinaridade vem assumindo, simultaneamente, a significação de elemento integrador no currículo e de reforço ao currículo disciplinar, com fortes evidências das marcas científicas dessa disciplinaridade. Nesse sentido, não focalizamos o histórico da construção da noção pedagógica de interdisciplinaridade, questão já abordada em Lopes (2008). Destacamos, todavia, a força da noção de interdisciplinaridade como expressão de uma proposta inovadora e contemporânea, a despeito de as propostas pedagógicas vinculadas a essa noção fazerem parte do discurso curricular desde o século XIX, com a ideia de correlação entre as disciplinas, em Herbart e nos autores herbatianos (Pinar, Reynolds, Slattery, \& Taubman, 1995). 
Retomamos aqui o foco nos documentos citados - PCNEM, PCN+ e OCNEM -, operando com eles como textos que fazem parte de um contexto mais amplo das políticas. Embora tais documentos tenham sido difundidos em distintos governos, optamos por abordá-los conjuntamente, uma vez que não os interpretamos como produtos de políticas distintas. Tratamos, nesta pesquisa, todas essas propostas como momentos de um texto político mais amplo, que busca produzir uma orientação para o Ensino Médio, tenta fixar uma dada significação curricular e, com isso, não cessa de produzir sentidos díspares em distintos contextos.

Pensamos tais documentos como tentativas de representação - sempre provisória, precária e contingente - da política, uma vez que se constitui por intermédio de articulações de demandas atinentes à heterogeneidade social (Laclau, 2011). Toda representação expressa a negociação de sentidos com os espaços representados no caso, o currículo das escolas. Tendo em vista esse caráter de representação do currículo, buscamos nos afastar do entendimento do currículo como um dado a ser ponderado, um fato a ser descrito, uma alternativa a ser defendida.

Ainda que, como Goodson (2007), consideremos que frequentemente se opera nas políticas curriculares com padrões construídos em torno da aprendizagem primária e da prescrição, pretendemos nos contrapor a essa noção de currículo, sem separar, como o faz Goodson (1997), currículo ativo e pré-ativo. Defendemos que, mesmo quando os textos oficiais buscam ser prescritivos, nunca o são plenamente, sempre fracassam em sua pretensão, tornando pouco produtivas as dimensões ativa e pré-ativa como particularidades dicotômicas que se interpenetram. Currículo é um espaço-tempo de disputas, de busca por exercício de poder e territorialização discursiva (Macedo, 2006); é uma política cultural, um texto (Lopes \& Macedo, 2011), tornando toda política de currículo uma luta pela significação desse objeto nunca completamente objetivado ao qual nomeamos currículo.

Buscamos, assim, reforçar o diálogo com os registros pós-estruturais de Stephen Ball, nos afastando das análises estruturais que pressupõem haver uma relação determinada entre dado projeto social e histórico e uma proposta curricular. Concebemos tais projetos e propostas como historicamente ressignificados nas dinâmicas contingentes que impedem o fechamento último da objetivação do social.

Com Goodson $(1993,1997)$, focalizamos as disciplinas no tocante à ideia de interdisciplinaridade. Problematizamos, nesse sentido: a influência da comunidade disciplinar na definição das políticas para o Ensino de Geografia, tendo em vista a defesa 
de uma interpretação possível da interdisciplinaridade como característica da ciência geográfica. Tensionamos, todavia, a relação entre as disciplinas acadêmica e escolar com vistas à distensão da leitura de que possuem a mesma estrutura, o mesmo funcionamento e as mesmas finalidades sociais.

Consideramos a abordagem do ciclo de políticas de Stephen Ball (Ball, Bowe, \& Gold, 1992), por sua vez, como possibilidade interpretativa dos documentos em foco, como via de compreensão dos movimentos políticos dinamizados por diferentes atores sociais envolvidos com o campo da Geografia. Acionamos o ciclo de políticas como uma via teórico-metodológica, pela oportunidade que abre à ideia de que a produção de textos/discursos/políticas se desdobra em um ciclo dinâmico e flexível, organizado em contextos distintos, mas que mantêm contínua relação. Lançamos mão do ciclo de políticas não como uma teoria rígida, estrutural, mas fortalecendo sua possibilidade, como uma interpretação fluida, uma compreensão heurística da produção das políticas. Destacamos não ser esta a única interpretação possível de ser apropriada, mas uma dentre distintas outras possibilidades.

Nesse sentido, atentamos ao contexto de definição de textos, caracterizado, na investigação que realizamos, como o dos órgãos de gestão. Particularmente, focalizamos o Ministério da Educação como espaço-tempo emblemático que, influenciado também por diferentes grupos de pesquisa universitária (Spósito, 1999) e pela produção acadêmica em geral - tanto aquelas voltadas às questões científicas como às da educação -, propõe documentos e pronunciamentos políticos com assinatura oficial, legitimando leituras hibridizadas de pesquisadores, educadores e demais vinculações políticas influenciadas por diferentes bandeiras e frentes de militância. Com isso, não operamos com a ideia de que há uma apropriação dos textos oficiais pela comunidade disciplinar. Diferentemente, concebemos a comunidade disciplinar como participante, em dadas relações de poder, do processo de elaboração dos textos oficiais, seja por uma ação direta, seja pelo processo social de circulação de múltiplos discursos disciplinares.

Para pensar o caráter híbrido das propostas com assinatura oficial, alinhamo-nos às discussões de Dias (2009), ao entender que, por serem documentos que demandam legitimação no processo de negociação e conflito entre diferentes sujeitos, são marcados por ambivalências e contradições, matizando-se como resultado dos embates de posição que constituem esse processo. Argumentamos que tal perspectiva insere uma forma diferenciada de apreender os textos oficiais, muitas vezes apon- 
tados como desorganizados epistemologicamente, incoerentes em suas propostas, aleatórios ou ecléticos em sua elaboração (Oliveira, 1999).

É com esta leitura que pensamos a produção dos PCNEM, dos PCN+e das OCNEM. Incorporamos a esta discussão a perspectiva de Ball (1994) da política como texto, por meio da qual os documentos com assinatura oficial são interpretados como representação precária da política. Ainda com Ball, compreendemos tais documentos como trechos da política, como sintomas de processos de bricolage, ressaltando a ambivalência e a incoerência em que se moldam as políticas. Com tal perspectiva, interpretamos a interdisciplinaridade como um componente organizador do currículo e buscamos compreender sua configuração e os sentidos possíveis na proposta comum à área de Ciências Humanas e naquela específica para Geografia.

Além disso, chamamos a atenção às comunidades disciplinares, argumentando sobre a importância de que elas sejam pensadas como produtoras das políticas nos vários contextos em que operam. Estamos comprometidos, todavia, com a leitura da comunidade disciplinar não como uma corporação consciente e orientada por uma episteme ou sustentada por uma história fundamental, mas como uma subjetivação política precipitada na contingência (Costa \& Lopes, no prelo).

Com essa abordagem, não sugerimos restringir a responsabilidade pela elaboração dos documentos a um segmento, um contexto sociopolítico ou um ator específico. Na busca pela influência na definição dos textos oficiais, tem-se a disputa, a negociação, a hibridização de diferentes perspectivas e sentidos de educação, independentemente das tentativas de fixação e/ou restrição das formas de interpretação. Pensamos, com Derrida (2006), que todo envolvimento na política implica responsabilização, mas ela não diz respeito a um saber absoluto sobre a política. Tal entendimento nos impede de controlar desdobramentos possíveis, embora estejamos envolvidos e, portanto, expostos ao questionamento da alteridade. Uma proposta apresentada como oficial será sempre composta por matizes e nuanças distintas e contraditórias, imbricadas na tentativa de um consenso que, mesmo quando pressuposto e desejado, é impossível plenamente, já que se torna obrigatoriamente marcado pelo conflito (Mouffe, 1996).

\section{Sobre as políticas}

No trecho comum a todas as disciplinas da área de Ciências Humanas (Geografia, Filosofia, História e Sociologia) dos PCNEM (MEC, 1999), é defendida a ideia de inter- 
disciplinaridade como sendo uma característica própria da área. Argumenta-se em favor de ideias como a de que existe uma predisposição à integração entre as disciplinas do campo das ciências humanas, o que supostamente já poderia ser considerado um aspecto facilitador na perspectiva de um currículo interdisciplinar. De maneira a apoiar esta leitura, torna-se emblemática uma visão específica sobre os objetos de estudo das referidas disciplinas, tal como em:

0 trabalho e a produção, a organização e o convivio sociais, a construção do "eu" e do "outro" são temas clássicos e permanentes das Ciências Humanas e da Filosofia. Constituem objetos de conhecimentos de caráter histórico, geográfico, econômico, político, jurídico, sociológico, antropológico, psicológico e, sobretudo, filosófico. Já apontam, por sua própria natureza, uma organização interdisciplinar[itálicos nossos]. (MEC, 1999, p. 9)

Simultaneamente à defesa da abordagem interdisciplinar tem-se, no texto específico de Geografia, não só um reforço ao currículo disciplinar, mas uma definição geográfica de seu objeto de estudos: “o espaço geográfico..., conjunto indissociável de sistemas de objetos (redes técnicas, prédios, ruas) e de sistemas de ações (organização do trabalho, produção, circulação, consumo de mercadorias, relações familiares e cotidianas) [itálicos nossos]". (MEC, 1999, p.30)

Se em dado momento há a definição de seu objeto específico, em outro é colocada a ideia de que a "Geografia em si já é um saber interdisciplinar" [itálicos nossos] (MEC, 1999, p. 31). Com esta justificativa, toma-se como pressuposto a noção de que há "necessidade de transcender seus limites conceituais e buscar a interatividade com as outras ciências sem perder sua identidade e especificidade” (MEC, 1999, p. 31). Argumenta-se, ainda nessa perspectiva, que o objeto da Geografia estaria dilacerado em todas as disciplinas da área, justificando, portanto, uma feição interdisciplinar que lhe seria própria. Assim,

sua busca por pensar o espaço enquanto totalidade, por onde passam todas as relações cotidianas e onde se estabelecem as redes sociais nas diferentes escalas, requer esse esforço interdisciplinar. 0 espaço e seu sujeito são constituídos por interações e seu estudo deve ser, por isso, interdisciplinar. 0 conhecimento geográfico resulta de um trabalho coletivo que envolve o conhecimento de outras áreas. (MEC, 1999, p. 32) 
Dessa forma, apoia-se a interdisciplinaridade da/na Geografia, reiterando seu caráter interdisciplinar e mantendo, assim, a tensão entre o currículo disciplinar e o integrado.

Em uma perspectiva de continuidade e complementação aos PCNEM, foram lançados os PCN+ (MEC, 2002). Nesse documento, assim como já explicitado, há uma continuidade na proposta de currículo integrado. Na defesa da integração curricular, há uma ressalva quanto à manutenção dos aspectos disciplinares e o reconhecimento de que a própria noção de interdisciplinaridade não prescinde das disciplinas. Como um de nós já discutiu (Lopes, 2008), a ideia de interdisciplinaridade tem sido entendida, nas atuais políticas para o Ensino Médio, como sinônimo de currículo integrado. Ao invés de ser destacado que a integração pode ser desenvolvida por diferentes formas de organização do currículo, destaca-se a interdisciplinaridade como a única possibilidade de integração para o nível médio de ensino. Mesmo quando é feita a menção à organização curricular por competências, não são salientadas suas possibilidades integradoras. Talvez, justamente, por ser a interdisciplinaridade a forma de integração que menos riscos traz à organização disciplinar, tão fortemente característica desse nível de ensino.

No texto de Geografia dos PCN+, assim como no texto comum à área de Ciências Humanas nesse documento, há predominância do discurso das competências. Ao longo desse, define-se a interdisciplinaridade como elemento fundamental para a resolução de problemas científicos. É com base nessa argumentação que também se desenvolve a justificativa para o ensino da disciplina no nível médio, alinhando, portanto, o Ensino Médio às finalidades e aos enfoques científicos.

Ao fazer menção aos conceitos estruturantes da proposta, reitera-se o esmero científico, ao afirmar que "na realidade, trata-se de um conjunto de conceitos que se encaixa com nitidez nos objetivos do ensino da disciplina no Ensino Médio e com as próprias características essenciais da Geografia como ciência” (MEC, 2002, p. 52). Ao argumentar sobre tais conceitos, tem-se a justificativa de que a "opção por conceitos e não por definições estanques é essencial para estruturação da Ciência Geográfica" (MEC, 2002, p. 55). Igualmente, ao definir a disciplina, é reforçado seu "caráter eminentemente científico" (MEC, 2002, p. 57). A argumentação dessa cientificidade cria uma via de legitimação da disciplina.

Junto com a interdisciplinaridade, são propostas competências como elementos auxiliares na integração curricular. No entanto, sugere-se, ao desenvolvê-las, uma abordagem marcadamente disciplinar, como nos exemplos seguintes (MEC, 2002): 
- Reconhecer os fenômenos espaciais a partir da seleção, comparação e interpretação, identificando as singularidades ou generalidades de cada lugar, paisagem e território. (p. 62)

- Compreender e aplicar no cotidiano os conceitos básicos da Geografia. (p. 63)

De semelhante modo, em uma perspectiva de retomada, crítica e aprofundamento da discussão dos Parâmetros Curriculares Nacionais para o Ensino Médio (MEC, 1999), foram lançadas as Orientações Curriculares Nacionais para o Ensino Médio (MEC, 2006). Neste documento, ao aprofundar a abordagem interdisciplinar, há não só uma vinculação desta à ideia de resolução de problemas, como uma defesa da transposição didática, reforçando o discurso disciplinar acadêmico como norte do saber escolar, a exemplo de:

Tais parâmetros e referências devem ajudar o professor a entender a importância da transposição didática do conhecimento científico, para que o aluno possa dele se apropriar .... Além disso, deve promover mudanças concretas que resultem em novos padrões de aprendizagem ... que se referencie em resoluções de problemas em perspectiva interdisciplinar. (MEC, 2006, p. 47)

Em outro trecho, ao referir-se às linguagens e às possibilidades de leitura do mundo, assim como nos PCNEM, se pressupõe a interdisciplinaridade como atributo do pensamento geográfico:

Essas linguagens (cartográfica, textual, corporal e cênica, iconográfica e oral) servirão de apoio para as aulas de Geografia, ... são um instrumento mais adequado para fazer a leitura do meio geográfico e de seu uso, o que supõe o exercício da interdisciplinaridade. (MEC, 2006, p. 50)

Para além da pretensão ao aprofundamento das discussões vistas como iniciadas nos PCNEM e, supostamente, aprimoradas nos PCN+, nas OCNEM é salientada uma prevalência do discurso acadêmico como legítimo, a ser aplicado como saber escolar, conforme mencionado na citação anterior. Por essa razão, focalizamos as tensões entre as disciplinas acadêmicas e as escolares, tendo em vista favorecer a ruptura com a ideia de que são a mesma disciplina em contextos diferentes ou de que o conhecimento escolar se legitima apenas como via de acesso ao conhecimento científico. 


\section{Sobre disciplinas e finalidades sociais}

Atentamos para a influência do discurso científico nas propostas para o Ensino Médio e, visando aprofundar essa discussão, recorremos às formulações de Goodson (1997). Esse autor argumenta que, de modo geral, as disciplinas são constituídas sócio-historicamente como respostas a demandas sociais, sejam essas demandas originadas no contexto acadêmico, científico ou escolar. Daí o fato de não existir uma relação identitária, e até mesmo genética, entre as disciplinas escolares e acadêmicas ou científicas, uma vez que os elementos de regulação desses contextos são entendidos como distintos. Entretanto, em concordância com Goodson (1997), ressaltamos que as disciplinas escolares tendem a se aproximar das disciplinas acadêmicas, numa busca por status, territórios e recursos, matizando relações de poder e controle e desenvolvendo, simultaneamente, padrões de estabilidade e mudança curricular.

Como já desenvolvido em Lopes (2008), argumentamos que as disciplinas não expressam apenas espaços epistemológicos, mas são, sobretudo, produções políticas e sócio-históricas de comunidades heterogêneas que mobilizam interesses e se articulam discursivamente em prol do desenvolvimento e da propulsão de suas bandeiras, perspectivas de mundo, de educação, de currículo e de ensino de Geografia. Embora a proposta de integração curricular seja sugerida enfaticamente pela via da interdisciplinaridade, os documentos genéricos, assim como os elementos supostamente capazes de dar conta da almejada integração, apresentam-se, nos trechos específicos para Geografia, hibridizados ao discurso disciplinar.

Nesse sentido, questionamos se a perspectiva de interdisciplinaridade, comum a toda a área de Ciências Humanas, ao se mostrar influenciada pela discussão acadêmica, não estaria sendo, nos documentos específicos, particularmente interpretada sob a lógica disciplinar geográfica, uma vez que se defende a interdisciplinaridade como uma peculiaridade epistemológica do conhecimento acadêmico-científico, tal como desenvolvido por Andrade (1987), ao afirmar que a Geografia, por estudar a relação entre a sociedade e a natureza, possui áreas comuns com os dois grandes grupos científicos (o das ciências sociais e o das ciências naturais). Ou, como em Claval (1982), que, em defesa da ideia de que a Geografia é uma ciência interdisciplinar, argumenta que seu objeto está disseminado no campo das ciências humanas, sociais e naturais, e que a "Geografia participa na ambiguidade fundamental de todas as ciências" (p. 17). 
A interdisciplinaridade, nessa perspectiva, estaria operando, ao mesmo tempo, como um elemento integrador no currículo e como um reforço ao currículo disciplinar. Princípios defendidos nos próprios documentos, tal como o de que a Geografia é em si um saber interdisciplinar, e também os discursos científicos sobre a gênese da própria ciência geográfica colaboram para que esse sentido possa permear as propostas aqui estudadas e seja suposto, em dada ocasião, como lugar comum nas discussões quanto à organização, às formas de pensar, ensinar e argumentar sobre a disciplina. É a partir dessa noção que problematizamos a interlocução da comunidade disciplinar de Geografia na produção das políticas de currículo para o ensino dessa disciplina.

Em trabalho anterior (Costa \& Lopes, 2009), argumentamos que as comunidades disciplinares contribuem para estabilizar, ainda que provisoriamente, determinados sentidos nos documentos com assinatura oficial, na intenção de defender suas demandas e interesses, no que tange a sua concepção sobre qualidade de ensino. Tal influência se dissemina em distintos contextos, e enfatizamos que, em função das hegemonias provisórias constituídas na relação com a disciplina, importa chamar a atenção para perspectivas que reduzem a produção do conhecimento na escola à circunscrição de certa leitura acadêmico-científica. Tal crítica não consiste em supor uma capacidade absoluta de determinada leitura de mundo saturar distintos contextos, mas assinala sua potencialidade em projetar territorialidades, no que toca à produção do conhecimento.

Ressaltamos que tais comunidades não são homogêneas, não comungam das mesmas perspectivas, dos mesmos valores e interesses, mas são fraturadas e apresentam embates quanto à significação do campo, estabelecendo acordos via negociação (Goodson, 1997). Esses embates não se fecham, mas continuam nas leituras e nas obrigatórias traduções dos textos políticos, sendo reiterada, assim, a feição ambivalente e rasurada da política.

Do mesmo modo, defendemos ser interessante conceber a comunidade disciplinar como formada não só pelos indivíduos praticantes da disciplina (os profissionais/ praticantes disciplinares), mas por todas as identificações envolvidas nos processos de (re)produção das políticas para Geografia. Propomos pensar a comunidade disciplinar como composta por todo envolvimento na produção das políticas para o ensino de Geografia, independente de ser/estar vinculado institucionalmente ao campo disciplinar ou de possuir uma 'história' com a disciplina. 
Com tais considerações, apontamos o quanto as perspectivas de disciplina escolar, de conhecimento escolar geográfico e interdisciplinaridade têm sido associadas ao discurso acadêmico. E o quanto essa associação é apresentada como garantia da qualidade do ensino a ser ministrado. Nos PCNEM, ao tratar tal questão, recorre-se a aspectos estruturais da disciplina acadêmica, ao se argumentar que

deu-se, então, importante experiência interdisciplinar, unindo-se historiadores, economistas, geógrafos e sociólogos, no esforço de tentar entender as razões da crise. É rico de lições perceber que ... as Ciências Humanas buscassem a alternativa interdisciplinar como solução para seus impasses. Desse enriquecimento, surgiram abordagens diversas e inovadoras, em antropohistória, geohistória, sociolingüística, história e geografia econômicas etc. (MEC, 1999, p. 7)

No texto das Orientações, é inserida a ideia de que o saber escolar geográfico deve ser pautado no conhecimento científico e, para isso, argumenta-se que "o ensino da Geografia deve fundamentar-se em um corpo teórico-metodológico baseado nos conceitos ..., incorporando também dimensões de análise que contemplam tempo, cultura, sociedade, poder e relações econômicas e sociais e tendo como referência os pressupostos da Geografia como ciência" [itálicos nossos] (MEC, 2006, p. 43).

É enfatizada, também, a necessidade de condições para que o "conhecimento seja construído em nível científico" (MEC, 2006, p. 48). É posto, ainda, o imperativo de maior comprometimento com a "dimensão epistemológica e ontológica da ciência geográfica” (p. 50).

Levando em conta as afirmativas anteriores, atentamos à discussão de Lopes (2002), quando critica a compreensão de que, embora sejam entendidas como formas pedagogizadas para fins de ensino, as disciplinas escolares são apreendidas como uma extensão dos saberes de referência, possuindo lógica interna e finalidades oriundas desses saberes. Com isso, as críticas feitas à especialização dos saberes científicos são levadas para o contexto escolar, como se os fatores de definição de um contexto (o científico) fossem válidos para a reprodução em outro, tal como o escolar.

Concordamos com essa discussão, por também entendermos que a significação da disciplina é diferente no âmbito escolar e no acadêmico-científico. Ao desconsiderar as distintas formas de operação contextuais das disciplinas, incorre-se no risco de plasmar as finalidades sociais do conhecimento escolar geográfico com as do co- 
nhecimento acadêmico e científico e, ao fazê-lo, incidir em distorções nas formas de conceber a epistemologia escolar geográfica. Esse risco é ainda maior, se levarmos em consideração a leitura de Goodson $(1993,1997)$ de que, na hierarquização social das disciplinas, a escolar é a de menor status.

A organização disciplinar do currículo, ao mesmo tempo em que é amplamente aceita, sendo interpretada como a perspectiva de maior êxito na organização do conhecimento (Lopes \& Macedo, 2011), é também muito criticada, normalmente a partir da ideia de que reitera uma visão de mundo fragmentária, parcial e, consequentemente, pouco capaz de dar conta de uma explicação complexa da vida social. Dessas contestações e preocupações com o currículo disciplinar surgiu, dentre outras, a proposta de integração. Nessa perspectiva, as disciplinas escolares tendem a ser pensadas como o próprio campo do saber delimitado, identificado com o conhecimento científico, e não como uma tecnologia de organização curricular.

Como desenvolvido em Lopes (2002), ao julgar a perspectiva integrada do currículo escolar como sendo pensada a partir da integração de conceitos, estruturas, formas e domínios do saber de referência, as disciplinas escolares têm sua organização situada no conhecimento de referência. Ou seja, é também nesse domínio que são analisadas as possibilidades de integração.

A visão de currículo integrado, que valoriza as disciplinas individuais e suas inter -relações, se associa hoje à noção de interdisciplinaridade. Pontuamos que a busca pela integração curricular se dá, também, com base na justificativa de que, no contexto atual do paradigma pós-fordista, há necessidade de indivíduos polivalentes, formados com base nas habilidades e nas competências mais complexas e superiores, que, por sua vez, seriam formadas de modo plausível numa perspectiva integrada (Lopes, 2008). Simultaneamente, entendemos que o processo de produção de conhecimento se dá de modo cada vez mais integrado. Assim, interessa reconhecer a pressuposição de que as pessoas devem ser formadas a partir dessa matriz. Esta argumentação se evidencia em premissas como a de que no Ensino Médio se busca “um perfil de formação do aluno mais condizente com as características da produção pós-industrial” (MEC, 1999, p. 102).

\section{Conclusões}

A partir da discussão desenvolvida até aqui, concluímos em relação ao caráter híbrido de produção dos textos curriculares com registro oficial e chamamos a atenção 
para o fato de que, apesar de terem sido elaborados em períodos distintos, apresentam em comum a perspectiva de integração curricular, baseada também na interdisciplinaridade como dispositivo integrador, e a manutenção simultânea do currículo disciplinar como organização do conhecimento, ainda que hibridizada em algumas noções de competência.

Defendemos que se desdobram hibridismos, não só das perspectivas do currículo integrado com o currículo disciplinar, mas, especificamente, entre os elementos entendidos como integradores e os conteúdos e as marcas disciplinares de Geografia. Argumentamos que a leitura de interdisciplinaridade dos documentos tende, simultaneamente, a se relacionar à possibilidade de integração na área de Ciências Humanas, dados os supostos objetos comuns entre as disciplinas da área. No entanto, nos textos específicos para Geografia, a interdisciplinaridade é apropriada pelo discurso disciplinar geográfico, delineando-a como uma característica da própria disciplina. Desse modo, entendemos a interdisciplinaridade como um reforço simultâneo à integração curricular e uma base de apoio ao discurso disciplinar, mantendo-se a ambivalência entre eles.

Ressaltamos, contudo, que no texto dirigido especificamente à Geografia é defendida a capacidade interdisciplinar dessa disciplina com base no discurso científico, numa busca pela resolução de problemas. Segundo Santomé (1998), esse processo pode acabar levando à formação de novas disciplinas, como um resultado da própria especialização científica.

Questionamos em que nível a perspectiva de interdisciplinaridade, considerada como uma marca genética da ciência geográfica (Moreira, 2006), estaria, tal como reconhecido por Goodson (1997), ao se aproximar da disciplina escolar, contaminando-a e influenciando a produção de sentidos que, no processo de hibridização, estariam viabilizando a legitimação da ideia de integração curricular na área. Nesse processo, e considerando a perspectiva do ciclo de políticas (Ball, Bowe, \& Gold, 1992), atentamos à comunidade disciplinar em sua capacidade de influenciar discursos das políticas.

Como forma de posicionamento de outra questão possível nesse cenário, questionamos se não seria no que Goodson chama de busca por status, território e recursos que a disciplina escolar se aproximaria da científica, apropriando-se desse discurso interdisciplinar, para manter-se e legitimar-se no currículo oficial. E, ainda, se não estaria, ao se referir ao saber geográfico, remetendo-se à noção de interdisciplinaridade 
como um todo para a área, buscando, assim, apoio no texto disciplinar para embasar a integração curricular.

Dada a capacidade de abertura do significante interdisciplinaridade para abarcar sentidos variados de Geografia e demais textos comuns da área, julgamos ser interessante entendê-lo como um significante, um nome flutuante (Laclau, 2011), visto que, em busca de adesão e legitimação provisória, o termo é delineado, simultaneamente, como traço disciplinar e como elemento integrador do currículo. Seria viabilizado, assim, o atendimento de demandas particulares, aspirando, ainda, à universalidade, ao incorporar sentidos dos diferentes discursos. Apoiamo-nos neste autor para entender que tal movimento representa o embate por hegemonia no currículo e, no caso da interdisciplinaridade, atuaria como uma relação de equivalência, pela qual as diferenças seriam minimizadas, ao negociarem a significação do termo contra o que interpretam como antagonismo, uma ameaça à identidade da disciplina e da própria comunidade disciplinar.

Limitamos essa discussão, entendendo interdisciplinaridade como um significante que, ao articular sentidos diferenciais, atuaria provisoriamente como estabilização e manutenção do conflito entre o currículo disciplinar e o integrado, realçando a hibridização em que se consolidam as políticas de currículo para o nível médio e, neste, para o ensino de Geografia. Finalizamos, enfatizando que a comunidade disciplinar, como subjetivação política, deve ser compreendida como relevante interlocutora na dinamização da política, fazendo com que, de forma híbrida e ambígua, o discurso disciplinar seja reforçado pelo discurso de integração curricular. 


\section{Referências bibliográficas}

Andrade, M. C. de. (1987).Geografia, ciência da sociedade: uma introdução à análise do pensamento geográfico (246 pp.). São Paulo: Atlas.

Ball, S. (1994). Education reform: a critical and post-structural approach (165 pp.). Buckingham: Open University.

Ball, S. (1998, March). Big policies/small world: an introduction to international perspectives in education policy. Comparative Education, 34(2), 119-30.

Ball, S., Bowe, R., \& Gold, A. (1992). Reforming education \& changing school: case studies in policy sociology (192 pp.). Londres - Nova York: Routledge.

Claval, P. (1982). A nova Geografia (163 pp.). Coimbra, Portugal: Porto Editora.

Costa, H. H. C., \& Lopes, A. C. (2009, janeiro/julho). Políticas de currículo para o ensino de Geografia: uma leitura a partir dos PCN para o Ensino Médio. Revista Contemporânea de Educação, 4(7), 196-215.

Costa, H. H. C., \& Lopes, A. C. (2011). Integração, interdisciplinaridade e Geografia em propostas curriculares nacionais. In A. C. Lopes, R. E. Dias, \& R. G. de Abreu. (Orgs.), Discursos nas políticas de currículo (pp. 77-92). Rio de Janeiro: Quartet.

Costa, H. H. C., \& Lopes, A. C. (2015). A comunidade disciplinar em Goodson: impasses em um registro pós-estrutural. Revista Brasileira de Educação.

Derrida, J. (2006). Dar la muerte (2a ed., 148 pp.). Barcelona: Paidós.

Dias, R. E. (2009). Ciclo de políticas curriculares na formação de professores no Brasil (1996-2006) (248ff.). Tese de Doutorado em Educação, Programa de Pós-Graduação em Educação, Universidade Estadual do Rio de Janeiro, Rio de Janeiro.

Goodson, I. (1993). School subject and curriculum change: studies in the social history of curriculum (2a ed., 256 pp.). London: The Falmer Press.

Goodson, I. (1997). A construção social do currículo. (111 pp., A. Nóvoa, org.). Lisboa: Educa.

Goodson, I. (2007, maio/agosto). Currículo, narrativa e o futuro social. Revista Brasileira de Educação, 12(35), 241-252. Retirado em 12 de dezembro de 2014, de http://www.scielo.br.

Laclau, E. (2011). Emancipação e diferença (222 pp.). Rio de Janeiro: Eduerj.

Lopes, A. C. (2002). Parâmetros curriculares para o ensino médio: quando a integração perde seu potencial crítico. In A. C. Lopes, \& E. F. Macedo (Orgs.), Disciplinas e integração curricular: história e políticas (pp. 145-176). Rio de Janeiro: DP\&A.

Lopes, A. C. (2008). Políticas de integração curricular (184 pp.). Rio de Janeiro: EdUERJ. 
Lopes, A. C., \& Macedo, E. (2011). Teorias de currículo. São Paulo: Cortez.

Macedo, E. (2006, maio/agosto). Currículo como espaço-tempo de fronteira cultural. Revista Brasileira de Educação, 11(32), 285-296.

Ministério da Educação e Cultura - MEC. Secretaria de Educação Média e Tecnológica - SEMTEC. (1999). Parâmetros Curriculares Nacionais para o Ensino Médio (4 vols., 75 pp.). Brasília: Autor.

Ministério da Educação e Cultura - MEC. Secretaria de Educação Média e Tecnológica - SEMTEC. (2002). Ciências Humanas e suas tecnologias (101 pp.). Ministério da Educação e Cultura/ Brasília: Autor.

Ministério da Educação e Cultura - MEC. Secretaria de Educação Básica - SEB. (2006). Orientações Curriculares Nacionais para o Ensino Médio (136 pp.). Brasília: Autor.

Moreira, R. (2006). Para onde vai o pensamento geográfico? Por uma epistemologia crítica (192 pp.). São Paulo: Contexto.

Mouffe, C. (1996). O regresso do político (192 pp.). Lisboa: Gradiva.

Oliveira, A. U. (1999). Geografia e ensino: Os parâmetros curriculares nacionais em discussão In: A. F. Carlos, \& A. U. Oliveira (Orgs.), Reforma no mundo da Educação - Parâmetros curriculares e geografia (pp. 43-67). São Paulo: Contexto.

Pinar, W., Reynolds, W. M., Slattery, P., \& Taubman, P. M. (1995). Understanding curriculum. New York: Peter Lang.

Santomé, J. T. (1998). Globalização e interdisciplinaridade: o currículo integrado.(274 pp.). Porto Alegre: Artes Médicas.

Spósito, M. E. B. (1999). Parâmetros curriculares nacionais para o ensino de Geografia: pontos e contrapontos para uma análise. In A. F. Carlos, \& A. U. Oliveira, (Orgs.), Reformas no mundo da educação: parâmetros curriculares e Geografia (pp. 19-35). São Paulo: Contexto.

Submetido à avaliação em 28 de fevereiro de 2015; aceito para publicação em 04 de junho de 2015. 
